\title{
Living Cationic Polymerization of 2-Phenoxyethyl Vinyl Ether and Its Ring-Substituted Derivatives: Effects of para-Substituents
}

\author{
Won Ok Chol, Mitsuo SAwamoto, and Toshinobu Higashimura* \\ Department of Polymer Chmeistry, Faculty of Engineering, \\ Kyoto University, Kyoto 606, Japan
}

(Received September 16, 1986)

\begin{abstract}
Three vinyl ethers with a $p$-substituted phenoxyl group in the pendant, $\mathrm{CH}_{2}=$ $\mathrm{CH}-\mathrm{O}-\mathrm{CH}_{2} \mathrm{CH}_{2}-\mathrm{O}-\mathrm{C}_{6} \mathrm{H}_{4} \mathrm{X}(p)\left(\mathrm{X}: \mathbf{1}, \mathrm{H} ; 2, \mathrm{OCH}_{3} ; 3, \mathrm{Cl}\right)$, formed living polymers with a narrow molecular weight distribution in the polymerization initiated by a mixture of hydrogen iodide and iodine $\left(\mathrm{HI} / \mathrm{I}_{2}\right)$ either in toluene at $-15^{\circ} \mathrm{C}$ or in methylene chloride at $-40^{\circ} \mathrm{C}$. The number-average molecular weight of the polymers increased in direct proportion to monomer conversion, and their molecular weight distribution stayed narrow $\left(\bar{M}_{w} / \bar{M}_{n}=1.1-1.3\right)$ independent of conversion. The rate of the homopolymerizations depended clearly on the $p$-substituents in the monomers and decreased in the order $\mathrm{OCH}_{3}(2)>\mathrm{H}(\mathbf{1})>\mathrm{Cl}$ (3). A similar but smaller dependence was observed in the copolymerizations of $\mathbf{1}$ with 2 and 3 initiated by $\mathrm{HI} / \mathrm{I}_{2}$ in toluene at $-15^{\circ} \mathrm{C}$ where living random copolymers with a narrow molecular weight distribution were obtained. According to a model reaction and ${ }^{13} \mathrm{C}$ NMR analysis of the monomers, their $p$-substituents affect not their reactivities but those of the propagating species, thereby resulting in great changes in the homopolymerization rates. In contrast to $1-3$, the corresponding nitro derivative $\left(4 ; \mathrm{X}=\mathrm{NO}_{2}\right)$ did not form a living homopolymer, but did give a living copolymer with 1 when polymerized by $\mathrm{HI} / \mathrm{I}_{2}$ in toluene at $-15^{\circ} \mathrm{C}$.
\end{abstract}

KEY WORDS Cationic Polymerization / Living Polymerization / Living

Copolymer / Monodisperse Polymer / 2-Phenoxyethyl Vinyl Ether / para-

Substituted 2-Phenoxyethyl Vinyl Ether / Hydrogen Iodide-Iodine Initiator /

"Living" cationic polymerization of vinyl ethers has recently been achieved with a mixture of hydrogen iodide and iodine $\left(\mathrm{HI} / \mathrm{I}_{2}\right)$ as an initiating system. ${ }^{1}$ Vinyl ethers that give living polymers include not only alkyl derivatives $\left(\mathrm{CH}_{2}=\mathrm{CH}-\mathrm{O}-i-\mathrm{C}_{4} \mathrm{H}_{9} \text {, etc. }\right)^{2,3}$ but those carrying polar functional pendants such as esters $\left(\mathrm{CH}_{2}=\mathrm{CH}-\mathrm{O}-\mathrm{CH}_{2} \mathrm{CH}_{2} \mathrm{OCOR}^{\prime}\right)^{4-6}$ and polyoxyethylenes $\left[\mathrm{CH}_{2}=\mathrm{CH}-\mathrm{O}\left(\mathrm{CH}_{2} \mathrm{CH}_{2} \mathrm{O}\right)_{n}\right.$ $\left.\mathrm{C}_{2} \mathrm{H}_{5}\right]^{7}$

An interesting but so far uninterpreted phenomenon in these polymerizations is that the overall reaction rate increases with the substituent $\mathrm{R}$ in the monomer in the order: ester $<$ alkyl $<$ polyoxyethylene. ${ }^{7}$ Although such a dependence apparently follows the conventional electronic effect of substituents on cationic polymerization of vinyl monomers (i.e., the more electron-donating the substituent is, the greater the overall rate), it cannot be so simply accounted for. For example, the polar functions (e.g., esters) in these vinyl ethers are separated from the vinyl group by two methylene units and an ether oxygen, so that they cannot affect the cationic reactivity of the monomers directly via inductive/resonance effects. In addition, ester, alkyl, and polyoxyethylene

* To whom all correspondence should be addressed. 
groups are so different from each other in electronic and steric structures that it is difficult to systematically discuss their effects on polymerization rate.

This study concerns the cationic homo- and copolymerization of 2-phenoxyethyl vinyl ether $(\mathbf{1})^{8}$ and its derivatives (2-4), a series of phenoxy-containing vinyl ethers with $p$ substituents ranging from an electrondonating methoxyl (2) to electronwithdrawing chloro (3) and nitro (4) groups.

$$
\begin{aligned}
& \mathrm{CH}_{2}=\mathrm{CH}-\mathrm{O}-\mathrm{CH}_{2} \mathrm{CH}_{2}-\mathrm{O}-\mathrm{O}-\mathrm{X} \\
& \mathrm{X}=\mathrm{H}, \quad \mathrm{OCH}_{3}, \quad \mathrm{Cl}, \quad \mathrm{NO}_{2} \\
& \begin{array}{lllll}
1 & 2 & 3 & 4
\end{array}
\end{aligned}
$$

We were primarily interested in (i) whether or not these vinyl ethers undergo living polymerization and (ii) how their $p$-substituents affect the reactivities of themselves and their propagating species in polymerization. For the second objective, vinyl ethers $1-\mathbf{4}$ are particularly suited, because one can introduce a variety of $p$-substituents into their phenyl ring without changing the basic structure of the vinyl ether skeleton. The possibility of the formation of living (random) copolymers of 1 with $2-4$ was also examined.

\section{EXPERIMENTAL}

\section{Materials}

Vinyl ethers $1-\mathbf{4}$ were prepared by the reactions of 2-chloroethyl vinyl ether with the corresponding phenols in dimethyl sulfoxide in the presence of sodium hydroxide. ${ }^{8}$ Monomers 1-3 were purified by double distillation over calcium hydride under reduced pressure; the nitro derivative $\mathbf{4}$ was repeatedly recrystallized from $98 \%$ ethanol and thoroughly dried in vacuo at room temperature. The gaschromatographic purities of these monomers were all better than $99 \%$; their structures were verified by ${ }^{1} \mathrm{H}$ and ${ }^{13} \mathrm{C}$ NMR spectroscopy and elemental analysis. Initiators [hydrogen iodide, iodine, and boron trifluoride etherate $\left(\mathrm{BF}_{3} \mathrm{OEt}_{2}\right)$ ] and solvents [toluene and methylene chloride $\left(\mathrm{CH}_{2} \mathrm{Cl}_{2}\right)$ ] were obtained as reported. $^{2,3}$

\section{Procedures}

Polymerization was carried out under dry nitrogen in a baked glass tube equipped with a three-way stopcock. ${ }^{2,3}$ The monomer conversion was determined from its residual concentration measured by gas chromatography with tetrahydronaphthalene $\left(2.5 \mathrm{vol}^{\circ} \%\right)$ as an internal standard. The molecular weight distribution (MWD) of the isolated polymers was measured by size-exclusion chromatography (SEC) in chloroform on a Jasco Trirotar-II instrument equipped with three polystyrene gel columns (Shodex A-802, A-803, and A-804). Their number-average molecular weight $\left(\bar{M}_{n}\right)$ and polydispersity ratio $\left(\bar{M}_{w} / \bar{M}_{n}\right)$ were calculated from the SEC curves on the basis of a polystyrene calibration. ${ }^{1} \mathrm{H}$ and ${ }^{13} \mathrm{C} \mathrm{NMR}$ spectra were recorded in $\mathrm{CDCl}_{3}$ at room temperature on a JEOL FX-90Q spectrometer.

The reaction of $\mathbf{1}$ and $\mathbf{3}$ with hydrogen iodide (eq 1 below) was carried out under dry nitrogen, similarly to the polymerization.

\section{RESULTS AND DISCUSSION}

\section{Living Homopolymerizations of Vinyl Ethers 1-3}

Monomers $1-3$ were polymerized by three cationic initiators $\left(\mathrm{HI} / \mathrm{I}_{2}, \mathrm{I}_{2}\right.$, and $\left.\mathrm{BF}_{3} \mathrm{OEt}_{2}\right)$ either in toluene at $-15^{\circ} \mathrm{C}$ or in $\mathrm{CH}_{2} \mathrm{Cl}_{2}$ at $-40^{\circ} \mathrm{C}$. In both solvents, the polymerizations proceeded without an induction phase up to $100 \%$ conversion. Figure 1 compares the timeconversion profiles for the three monomers with $\mathrm{HI} / \mathrm{I}_{2}$ as an initiating system. The overall rate of the polymerizations increased with increasing electron-donating power of the $p$ substituents in the monomers: $\mathrm{Cl}(3)<\mathrm{H}$ (1) $<\mathrm{OCH}_{3}$ (2). Similar dependences were observed when iodine and $\mathrm{BF}_{3} \mathrm{OEt}_{2}$ were employed as initiators. 

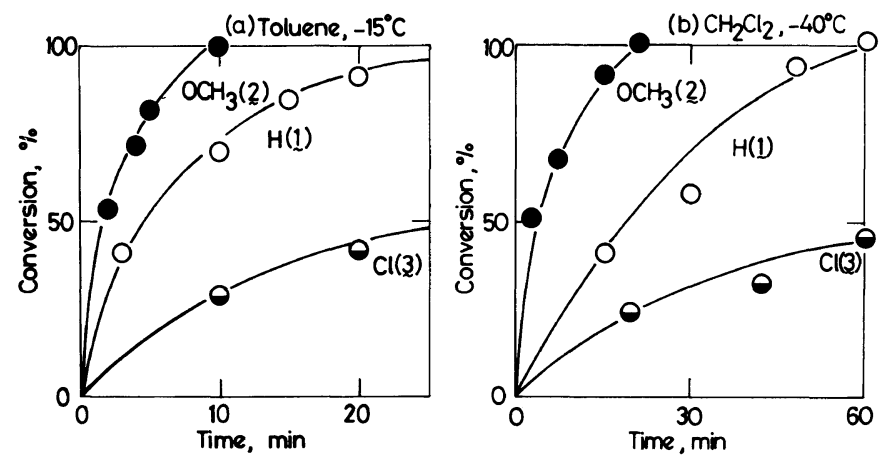

Figure 1. Time-conversion curves for the polymerizations of $\mathbf{1}-\mathbf{3}$ by $\mathrm{HI} / \mathrm{I}_{2}$ : (a) in toluene at $-15^{\circ} \mathrm{C}$; (b) in $\mathrm{CH}_{2} \mathrm{Cl}_{2}$ at $-40^{\circ} \mathrm{C}$. $[\mathrm{M}]_{0}=5.0 \mathrm{vol} \%(\mathrm{ca} .0 .3 \mathrm{M}) ;[\mathrm{HI}]_{0}=\left[\mathrm{I}_{2}\right]_{0}=5.0 \mathrm{mM}$. Monomers: $(\mathrm{O}) 2\left(\mathrm{X}=\mathrm{OCH}_{3}\right)$; (O) $1(\mathrm{X}=\mathrm{H})$; (Ө) $3(\mathrm{X}=\mathrm{Cl})$.

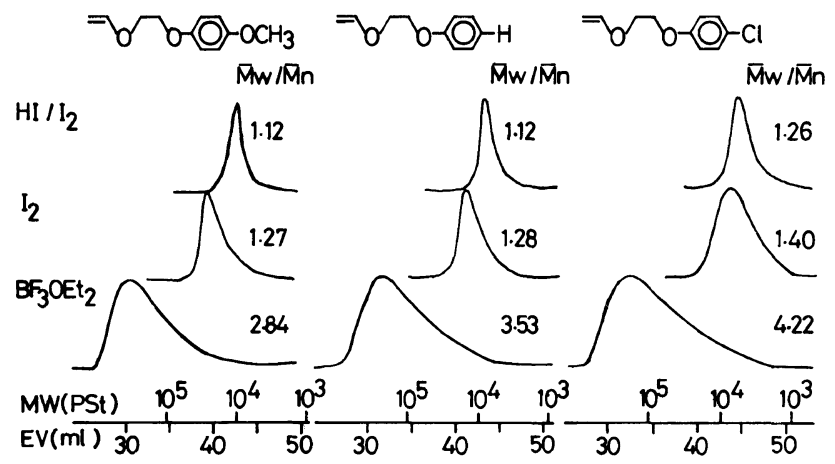

Figure 2. MWD of the polymers of $1-3$ obtained in toluene $-15^{\circ} \mathrm{C}$ with three initiators indicated: $[\mathrm{M}]_{0}=5.0 \mathrm{vol}^{\%}(\mathrm{ca} .0 .3 \mathrm{M})$; conversion $c a .100 \%$. Initiator concentration: $\mathrm{HI} / \mathrm{I}_{2}, 5.0 \mathrm{mM}$ each; $\mathrm{I}_{2}, 10 \mathrm{mM}$; $\mathrm{BF}_{3} \mathrm{OEt}_{2}, 1-2 \mathrm{mM}$.

Figure 2 illustrates the MWD of the polymers obtained by the three initiators in toluene at $-15^{\circ} \mathrm{C}$. From all monomers, $\mathrm{BF}_{3} \mathrm{OEt}_{2}$ produced high molecular weight polymers with a broad MWD $\left(\bar{M}_{w} / \bar{M}_{n}=2.8\right.$ 4.2). In contrast, the polymers obtained with $\mathrm{HI} / \mathrm{I}_{2}$ and iodine exhibited smaller molecular weights and narrower MWDs; in particular, $\mathrm{HI} / \mathrm{I}_{2}$ led to very narrow MWDs with $\bar{M}_{w} / \bar{M}_{n}=1.1-1.3$. Similar narrow MWDs were obtained in polymerizations by $\mathrm{HI} / \mathrm{I}_{2}$ in $\mathrm{CH}_{2} \mathrm{Cl}_{2}$ at $-40^{\circ} \mathrm{C}$ and otherwise under the same conditions. Separate experiments showed that raising the polymerization temperature to $-15^{\circ} \mathrm{C}$ in the same polar solvent results in a broadening of polymer MWD.

Noting these trends, we then studied the possibility of living polymerization of $1-3$ initiated by $\mathrm{HI} / \mathrm{I}_{2}$ which gave the narrowest MWDs of the polymers. Thus, we plotted in Figure 3 their $\bar{M}_{n}$ and $\bar{M}_{w} / \bar{M}_{n}$ values as a function of monomer conversion. Independent of the $p$-substituents in the monomers and the polymerization solvents employed, the polymer molecular weights were directly proportional to monomer conversion, and the MWDs were all narrow $\left(\bar{M}_{w} / \bar{M}_{n}=1.1-1.3\right)$.

${ }^{1} \mathrm{H}$ and ${ }^{13} \mathrm{C}$ NMR structural analysis of the polymers indicated that $\mathbf{1}-\mathbf{3}$ polymerize exclusively via their vinyl moieties without side reactions including those of the growing spe- 


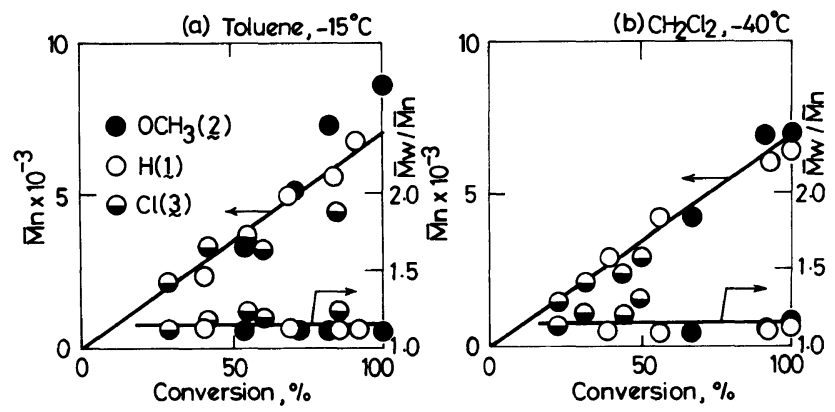

Figure 3. Conversion dependence of the $\bar{M}_{n}$ and $\bar{M}_{w} / \bar{M}_{n}$ of the polymers of $\mathbf{1}-\mathbf{3}$ obtained by HI/I $\mathrm{I}_{2}$ : (a) in toluene at $-15^{\circ} \mathrm{C}$; (b) in $\mathrm{CH}_{2} \mathrm{Cl}_{2}$ at $-40^{\circ} \mathrm{C}$. $[\mathrm{M}]_{0}=5.0 \mathrm{vol} \%($ ca. $0.3 \mathrm{M}) ;[\mathrm{HI}]_{0}=\left[\mathrm{I}_{2}\right]_{0}=5.0 \mathrm{mM}$. Monomers: (○) $2\left(\mathrm{X}=\mathrm{OCH}_{3}\right) ;(\bigcirc) 1(\mathrm{X}=\mathrm{H}) ;(\ominus) 3(\mathrm{X}=\mathrm{Cl})$.

cies with aromatic rings in the monomers or polymers.

All these facts show the formation of living polymers from vinyl ethers $\mathbf{1}-\mathbf{3}$ by $\mathrm{HI} / \mathrm{I}_{2}$ either in nonpolar toluene or in polar $\mathrm{CH}_{2} \mathrm{Cl}_{2}$ solvent. The nature of their $p$-substituents, ranging from a methoxy group in 2 to a chlorine in $\mathbf{3}$, does not apparently affect the living character of the polymerizations. Close inspection of Figure 2, however, indicates that monomer $\mathbf{3}$, having an electron-withdrawing chlorine in the pendant, gives MWDs somewhat broader than those for $\mathbf{1}$ and $\mathbf{2}$; the polymerization of $\mathbf{3}$ may be accompanied by a minor chain transfer.

In separate experiments, a fresh feed of $\mathbf{1 , 2}$, or $\mathbf{3}$ was added to a reaction mixture where the first feed of the same monomer had been completely polymerized by $\mathrm{HI} / \mathrm{I}_{2}$ in toluene at $-15^{\circ} \mathrm{C}$. As expected for living processes, a second-stage polymerization of the added monomer immediately ensued; however, the $\bar{M}_{n}$ 's of the produced polymers were smaller than those obtained by extrapolating the linear $\bar{M}_{n}$-conversion plot in Figure 3(a). Accordingly, the $\mathrm{HI} / \mathrm{I}_{2}$-initiated polymerizations of 1-3 may not be perfectly living.

A similar discrepancy from the living character in so-called monomer-addition experiments has been observed for vinyl ethers with a pendent polyoxyethylene chain, which are similar in structure to $\mathbf{1} \mathbf{- 3}$ in that they carry at least two electron-rich ether oxygens in the pendant. $^{7}$ It has been suggested ${ }^{7}$ that the propagating ends derived from these monomers may be intramolecularly solvated by the pendent ether oxygens and thereby be ionically more dissociated, more reactive, and in turn less stable than those from alkyl vinyl ethers.

\section{Copolymerizations of $\mathbf{1}$ with $\mathbf{2}$ and 3; Relative Reactivity of the Monomers}

As already shown in Figure 1, the rate of the living homopolymerizations of $\mathbf{1}-\mathbf{3}$ by $\mathrm{HI} / \mathrm{I}_{2}$ considerably depended on the $p$-substituents in the monomers; the greater their electrondonating power, the greater was the rate. To clarify such a substituent effect further, copolymerizations of the unsubstituted monomer 1 with the substituted ones (2 and 3) were studied. Figure 4 shows the timeconversion profiles for each comonomer in the $\mathrm{HI} / \mathrm{I}_{2}$-initiated copolymerizations in toluene at $-15^{\circ} \mathrm{C}$. The methoxy derivative 2 reacted faster than $\mathbf{1}$, whereas chlorine-containing 3 did slower than 1 . The same rate orders were obtained in copolymerizations initiated by iodine or $\mathrm{BF}_{3} \mathrm{OEt}_{2}$ and otherwise under the same conditions.

The consumption of monomers $\mathbf{1}-\mathbf{3}$ in both homo- and copolymerizations followed the first-order kinetics with respect to monomer. The relative rate of polymerization of each (co)monomer was then evaluated from the 

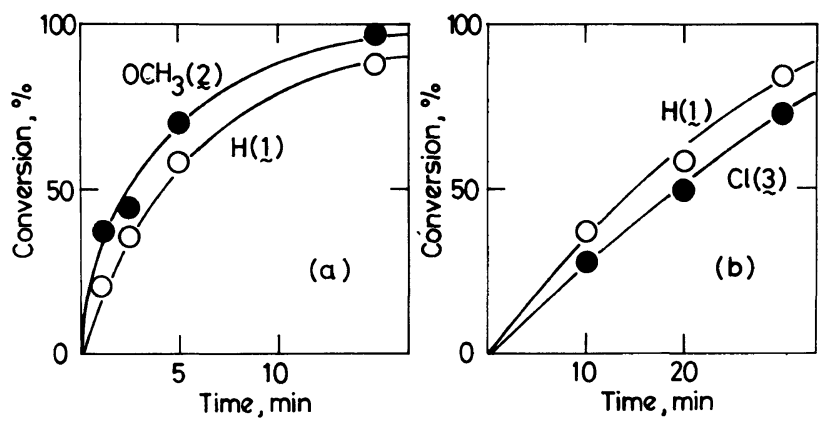

Figure 4. Time-conversion curves for the copolymerizations of $1(\mathrm{X}=\mathrm{H})$ with $2\left(\mathrm{X}=\mathrm{OCH}_{3}\right)$ (a) and with $3(\mathrm{X}=\mathrm{Cl})(\mathrm{b})$ initiated by $\mathrm{HI} / \mathrm{I}_{2}$ in toluene at $-15^{\circ} \mathrm{C}:[\mathrm{HI}]_{0}=\left[\mathrm{I}_{2}\right]_{0}=5.0 \mathrm{mM} ;[1]_{0}=[\text { comonomer }]_{0}=$ $2.5 \mathrm{vol}_{\%} \%$ (ca. $\left.0.15 \mathrm{M}\right)$.

Table I. Relative polymerization rates ${ }^{\mathrm{a}}$ in toluene at $-15^{\circ} \mathrm{C}$ and ${ }^{13} \mathrm{C} \mathrm{NMR}$ chemical shifts $(\delta)^{\mathrm{b}}$ of vinyl ethers $1-\mathbf{3}$

$$
{ }^{\beta} \mathrm{CH}_{2}={ }^{\alpha} \mathrm{CH}-\mathrm{O}-\mathrm{CH}_{2} \mathrm{CH}_{2}-\mathrm{O}-\mathrm{O}
$$

\begin{tabular}{|c|c|c|c|c|c|}
\hline \multirow{2}{*}{ Monomer (X) } & \multirow{2}{*}{$\frac{\text { Homopolymn }^{\mathrm{c}}}{\mathrm{HI} / \mathrm{I}_{2}^{\mathrm{e}}}$} & \multicolumn{2}{|c|}{ Copolymn with $\mathbf{1}^{\mathrm{d}}$} & \multicolumn{2}{|c|}{${ }^{13} \mathrm{C}$ NMR, $\delta(\mathrm{ppm})$} \\
\hline & & $\mathrm{HI} / \mathrm{I}_{2}{ }^{\mathrm{e}}$ & $\mathrm{BF}_{3} \mathrm{OEt}_{2}{ }^{\mathrm{f}}$ & ${ }^{\beta} \mathrm{C}$ & ${ }^{x} \mathrm{C}$ \\
\hline $2\left(\mathrm{OCH}_{3}\right)$ & 2.7 & 1.5 & 1.4 & 87.0 & 151.5 \\
\hline $1(\mathrm{H})$ & 1 & 1 & 1 & 86.8 & 151.4 \\
\hline $3(\mathrm{Cl})$ & 0.24 & 0.69 & 0.64 & 87.0 & 151.3 \\
\hline
\end{tabular}

a Determined, relative to $\mathbf{1}$, from the slope of the first-order plot for monomer consumption.

b Measured in $\mathrm{CDCl}_{3}$ at room temperature.

c $[\mathrm{M}]_{0}=5.0 \mathrm{vol} \%(\mathrm{ca} .0 .3 \mathrm{M})$.

d $[1]_{0}=[\text { comonomer }]_{0}=2.5 \mathrm{vol} \%$.

e $[\mathrm{HI}]_{0}=\left[\mathrm{I}_{2}\right]_{0}=5.0 \mathrm{mM}$.

f $\left[\mathrm{BF}_{3} \mathrm{OEt}_{2}\right]_{0}=0.50 \mathrm{mM}$.

slope of a linear first-order $[\log (100-\%$ conversion) vs. time] plot, and is listed in Table I. In all cases, the relative rate increased with increasing electron-donating power of the $p$ substituent in the monomer $\left(\mathrm{Cl}<\mathrm{H}<\mathrm{OCH}_{3}\right)$; the substituents affect the rate more in the homopolymerizations than in the copolymerizations.

In general, the homopolymerization rate is a function of the reactivities of both monomer and propagating species derived from it. As a measure of the reactivity of monomers, we took the ${ }^{13} \mathrm{C}$ NMR chemical shifts of their vinyl carbons (Table I) that, at least qualitatively, correlate with the electron density on the vinyl double bond. ${ }^{9}$ In contrast to the clear dependence of the polymerization rates on the $p$-substituents, the chemical shift values of the $\alpha$ - and $\beta$-carbons of $\mathbf{1}-\mathbf{3}$ were independent of them. It follows that the electron density of the vinyl groups of $\mathbf{1}-\mathbf{3}$ is not affected by their $p$ substituents; i.e., monomers $\mathbf{1}-\mathbf{3}$ are similar in polymerization reactivity.

The above conclusion was verified by a model reaction (eq 1) in which 1 and $\mathbf{3}$ were allowed to react competetively with hydrogen iodide as an electrophile. This model process is simpler and more suited for the evaluation of relative monomer reactivity in that it involves only a single electrophile (HI) to consume 1 and 3, whereas their copolymerization involves at least two electrophiles (growing ends) de- 
rived from the comonomers.
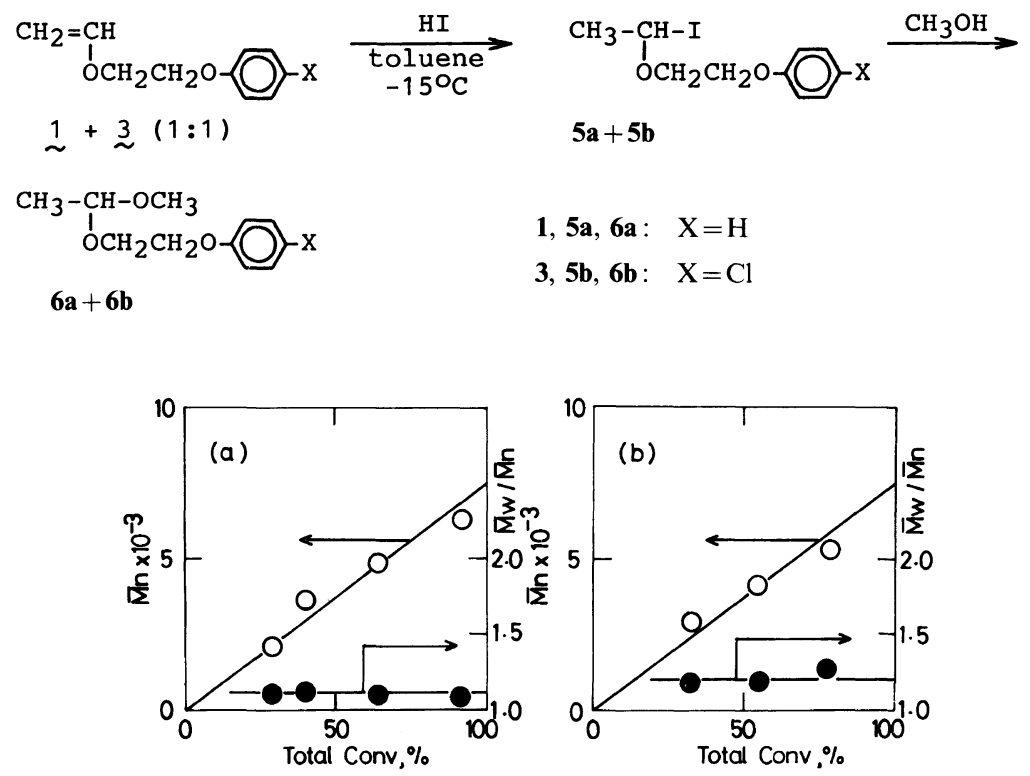

Figure 5. Conversion dependences of the $\bar{M}_{n}$ and $\bar{M}_{w} / \bar{M}_{n}$ of the copolymers of 1 with 2 (a) and with 3 (b) obtained by $\mathrm{HI} / \mathrm{I}_{2}$ in toluene at $-15^{\circ} \mathrm{C}:[\mathrm{HI}]_{0}=\left[\mathrm{I}_{2}\right]_{0}=5.0 \mathrm{mM} ;[1]_{0}=[\text { comonomer }]_{0}=2.5 \mathrm{vol} \%$ (ca. $0.15 \mathrm{M})$. Total monomer conversion $(\%)=100 \times($ weight of the comonomers polymerized $) /($ weight of the comonomers in feed).

In a typical run, an equimolar mixture of $\mathbf{1}$ and $3(0.20 \mathrm{M}$ each) was treated with $\mathrm{HI}$ $(0.080 \mathrm{M})$ in toluene at $-15^{\circ} \mathrm{C}$. Competetive addition of $\mathrm{HI}$ to $\mathbf{1}$ and $\mathbf{3}$ gives $\mathrm{HI}$ adducts $\mathbf{5 a}$ and $\mathbf{5 b}$, respectively. ${ }^{10}$ Since $\alpha$-haloether-type adducts 5 are not stable and may regenerate the corresponding vinyl ether and HI, they were converted in situ into more stable acetals 6 by quenching the reaction with prechilled methanol, and the consumption of each monomer was determined by gas chromatography. The conversions of $\mathbf{1}$ and $\mathbf{3}$ in $1 \mathrm{~min}$ were $22 \%$ and $21 \%$, respectively, indicating nearly the same reactivities of these monomers towards electrophiles. The molar sum of $\mathbf{1}$ and 3 consumed in the model reaction amounted to $0.086 \mathrm{M} \quad[=0.20 \mathrm{M} \times(0.22+0.21)]$, and was close to the initial dose of HI $(0.080 \mathrm{M})$. This agreement supports the quantitative addition of $\mathrm{HI}$ to $\mathbf{1}$ and $\mathbf{3}$ without the formation of polymers.
The above described results of the copolymerizations, ${ }^{13} \mathrm{C}$ NMR analysis, and the model reaction all show that the $p$-substituents in vinyl ethers $\mathbf{1}-\mathbf{3}$ affect not the reactivities of the monomers but those of their propagating species to result in the observed changes in their homopolymerization rates.

\section{Living Copolymers}

Noting the formation of living (homo)polymers from $1-3$ in the presence of $\mathrm{HI} / \mathrm{I}_{2}$, we then analyzed the moelcular weight of the copolymers of these monomers obtained by the same initiator to see whether they are living (Figure 5). The $\bar{M}_{n}$ 's of the polymers are directly proportional to the total monomer conversion; their MWDs were all narrow with $\bar{M}_{w} / \bar{M}_{n}$ ratios from 1.1 to 1.3 . Therefore, the $\mathrm{HI} / \mathrm{I}_{2}$ system leads to living polymers not only in homopolymerization but in copolymerization of vinyl ethers $1-3$. In view of their 

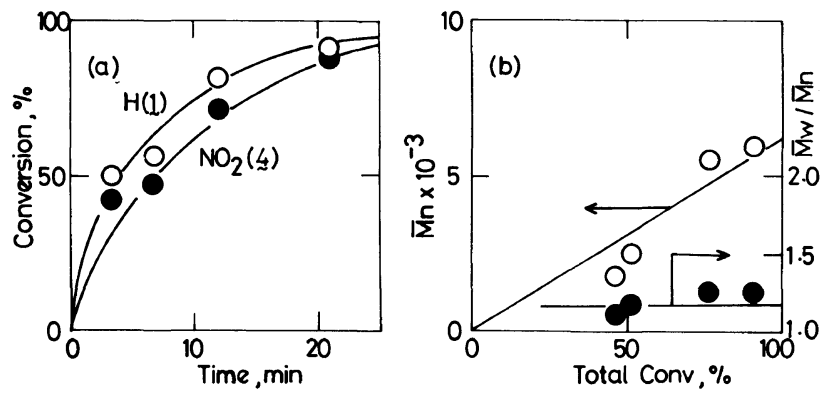

Figure 6. Copolymerization of $4\left(X=\mathrm{NO}_{2}\right)$ with $1(X=\mathrm{H})$ initiated by $\mathrm{HI} / \mathrm{I}_{2}$ in toluene at $-15^{\circ} \mathrm{C}$ : $[\mathrm{HI}]_{0}=\left[\mathrm{I}_{2}\right]_{0}=5.0 \mathrm{mM} ;[4]_{0}=[1]_{0}=0.15 \mathrm{M}$. (a) Time-conversion curve; (b) $\bar{M}_{n}$ and $\bar{M}_{w} / \bar{M}_{n}$ as a function of total monomer conversion.

narrow MWD, the copolymers are most likely random in nature. Recently we have obtained living randon copolymers between isobutyl vinyl ether and $p$-methoxystyrene using the same initiator. ${ }^{11}$ This study has given additional examples of cationic living random copolymerizations now between vinyl ethers.

Homo- and Copolymerizations of the Nitro

\section{Derivative 4}

Since the nitro group-containing monomer 4 turned out to differ in polymerization behavior from $1-3$, its results are treated separately in this section.

Despite its strongly electron-withdrawing nitro group in the para position, vinyl ether $\mathbf{4}$ was rapidly polymerized by $\mathrm{HI} / \mathrm{I}_{2}$ in toluene at $-15^{\circ} \mathrm{C}$; the conversion reached $\mathrm{ca} .90 \%$ in $10 \mathrm{~min}\left([4]_{0}=0.30 \mathrm{M}, \quad[\mathrm{HI}]_{0}=\left[\mathrm{I}_{2}\right]_{0}=5.0 \mathrm{mM}\right)$ and increased gradually with time. The molecular weight of the produced polymers, however, neither exceeded 3000 nor increased with monomer conversion; i.e., living polymers did not form from 4. The pendent $p$ nitrophenoxyl group in $\mathbf{4}$, similar in structure to nitrobenzene, may act as a highly polar solvent and thereby facilitate the formation of an ionically dissociated, less stable propagating species that undergoes chain transfer reaction(s).

In contrast to the unsuccessful living homopolymerization, 4 formed living copolymers when copolymerized with 1 (or 2 ) by $\mathrm{HI} / \mathrm{I}_{2}$ in toluene at $-15^{\circ} \mathrm{C}$; it is of interest but difficult to explain that the copolymerization of $\mathbf{4}$ is living, whereas its homopolymerization is not. Figure 6(a) shows the time-conversion curves for 1 and 4 obtained under these conditions. Both comonomers polymerized smoothly, 1 being consumed faster than 4 . The $\bar{M}_{n}$ of the copolymers [Figure 6(b)] increased proportionally to the total conversion of the two monomers, while their MWD remained narrow throughout the reaction.

\section{REFERENCES}

1. As reviews see (a) $T$. Higashimura and $\mathbf{M}$. Sawamoto, Adv. Polym. Sci., 62, 49 (1984); (b) idem, Makromol. Chem., Suppl., 12, 153 (1985); (c) M. Sawamoto and T. Higashimura, Makromol. Chem., Macromol. Symp., 3, 83 (1986); (d) T. Higashimura, S. Aoshima, and M. Sawamoto, ibid., 3, 99 (1986).

2. M. Miyamoto, M. Sawamoto, and T. Higashimura, Macromolecules, 17, 265 (1984).

3. M. Miyamoto, M. Sawamoto, and T. Higashimura, Macromolecules, 17, 2228 (1984).

4. S. Aoshima, T. Nakamura, N. Uesugi, M. Sawamoto, and T. Higashimura, Macromolecules, 18, 2097 (1985).

5. S. Aoshima, O. Hasegawa, and T. Higashimura, Polym. Bull., 13, 229 (1985).

6. S. Aoshima, O. Hasegawa, and T. Higashimura, Polym. Bull., 14, 417 (1985).

7. T. Nakamura, S. Aoshima, and T. Higashimura, Polym. Bull., 14, 515 (1985).

8. J. V. Crivello and D. A. Conlon, J. Polym. Sci., Polym. Chem. Ed., 21, 1785 (1983). 
9. (a) T. Higashimura, S. Okamura, I. Morishima, and T. Yonezawa, J. Polym. Sci., B, 7, 23 (1969); (b) H. Yuki, K. Hatada, K. Nagata, and T. Emura, Polym. J., 1, 269 (1970).
10. T. Higashimura, M. Miyamoto, and M. Sawamoto, Macromolecules, 18, 611 (1985).

11. M. Sawamoto, T. Ohtoyo, T. Higashimura, K.-H. Gührs, and G. Heublein, Polym. J., 17, 929 (1985). 